\title{
Grandes empresas e interculturalidade: importância do profissional de relações públicas no ambiente digital
}

Large companies and interculturalism: importance of the public relations professional in the digital environment

Grandes empresas e interculturalidad: importancia del profesional de relaciones públicas en el ambiente digital

(9) Fabiana Grieco Cabral de Mello Vetritti

- Doutoranda do Programa de Pós-Graduação em Ciências da Comunicação da Escola de Comunicações e Artes da Universidade de São Paulo (ECA-USP)

- Mestre em Comunicação e Semiótica pela Pontifícia Universidade Católica de São Paulo (PUC-SP)

- Pesquisadora associada do NAP Escola do Futuro - USP

- Filiada à Associação Brasileira dos Pesquisadores e Profissionais da Educomunicação (BPEducom)

- E-mail: fabianagrieco@yahoo.com.br

(9) Rafael Vergili

- Doutorando do Programa de Pós-Graduação em Ciências da Comunicação da Escola de Comunicações e Artes da Universidade de São Paulo (ECA-USP)

- Mestre em Comunicação pela Faculdade Cásper Líbero (Facásper)

- Pesquisador associado do NAP Escola do Futuro - USP e dos grupos de pesquisa "Tecnologia, comunicação e ciência cognitiva" (Tecccog), da Universidade Metodista de São Paulo (Umesp), e "Comunicação, tecnologia e mercado" (Comertec), da Universidade Federal do Amapá (Unifap)

- E-mail: rvergili@gmail.com 


\section{Resumo}

A internet alterou as formas de relacionamento entre grandes empresas e públicos de interesse. Com o aumento do acesso mundial à rede, quebra-se a barreira do tempo e do espaço, gerando integrações e apontamentos de diversas culturas nas diretrizes comunicacionais das organizações brasileiras, fatos que estão ligados à interculturalidade. Profissionais de relações públicas - teoricamente formados para promover diálogo e realinhamento de estratégias - têm baixa inserção nas atividades relativas ao ambiente digital, como apontam duas pesquisas (quantitativa e qualitativa) apresentadas no artigo.

\section{PALAVRAS-CHAVE: INTERCULTURALIDADE・GRANDES EMPRESAS・RELAÇÕES PÚBLICAS・INTERNET.}

\section{Abstract}

The internet has altered the forms of relationship between large companies and stakeholders. With the increase of access to the worldwide web, the barrier of time and space is shattered, generating integrations and notes of different cultures in communicational guidelines of Brazilian organizations, facts that are related to interculturalism. Public relations professionals - theoretically graduated to promote dialogue and realign strategies - have scarce participation in the activities related to the digital environment, as shown by two studies (quantitative and qualitative) presented in the article.

\section{KEYWORDS: INTERCULTURALISM・LARGE COMPANIES・PUBLIC RELATIONS・INTERNET.}

\section{Resumen}

El internet alteró las formas de relacionamiento entre grandes empresas y públicos de interés. Con el aumento del acceso mundial a la red, se rompe la barrera del tiempo y del espacio, generando integraciones y apuntamientos de distintas culturas en las directrices comunicacionales de las organizaciones brasileras, hechos que están relacionados a la interculturalidad. Profesionales de relaciones públicas - teóricamente graduados para promover el diálogo y la realineación de las estrategias - tienen una baja participación en las actividades relacionadas con el ambiente digital, como lo demuestran dos estudios (cuantitativos y cualitativos) presentados en el artículo. 
O

barateamento de máquinas computacionais e a consequente ampliação de acesso à rede em âmbito mundial tornam a noção de territorialidade cada vez mais fragmentada. Nesse sentido, percebe-se facilmente 0 aumento da velocidade de produção, consumo, compartilhamento e descarte de informações. Empresas inseridas nesse contexto tecnológico precisam adaptar suas formas de atuação, especialmente nos relacionamentos com públicos de interesse, também chamados de stakeholders. 0 impacto instantâneo que mensagens enviadas de qualquer parte do mundo, a qualquer momento, podem causar na imagem institucional faz com que, na perspectiva de Brasilina Passarelli (2010), organizações repensem estruturas sedimentadas em busca de alinhamento aos novos modelos de negócios, inextricavelmente ligados à internet.

Diante desse cenário, o presente artigo tem como objetivo principal promover reflexão acerca da importância do profissional de relações públicas na adaptação de grandes empresas às transformações provocadas no ambiente corporativo pela introdução de novas tecnologias e a consequente interculturalidade que o permeia.

Para isso, no decorrer de três grandes itens, além de revisão bibliográfica, o texto apresenta os resultados e as análises de duas pesquisas: uma quantitativa, com grandes empresas brasileiras, e outra qualitativa, com algumas das maiores agências de comunicação do mercado nacional.

No primeiro item, com auxílio de textos de Jacques Ellul (1993) e Miguel Rodrigo Alsina (2004), discute-se o fenômeno da interculturalidade e sua influência nas empresas brasileiras.

0 segundo item apresenta gráficos e análises referentes aos dados obtidos em pesquisa quantitativa realizada com 252 grandes empresas que atuam no território nacional e que possuem presença no ambiente digital. Nesse sentido, identificamse, especialmente: os objetivos das organizações no ambiente da web e o percentual de profissionais de relações públicas inseridos nesse nicho de mercado.

Por fim, o terceiro item contrasta conceitos de relações públicas externados por Maria Aparecida Ferrari (2006), Luiz Alberto de Farias (2009) e Margarida Maria Krohling Kunsch (2009), como parte de um panorama (de adaptações e mudanças corporativas contemporâneas) construído a partir de entrevistas em profundidade com representantes de algumas das maiores agências de comunicação brasileiras: CDN, Edelman Significa, FSB, Grupo Máquina PR, Grupo TV1 e In Press Porter Novelli.

\section{INTERCULTURALIDADE: DESAFIOS E OPORTUNIDADES}

Diante da transformação provocada pelo uso da internet no seio do âmbito informacional/comunicacional, sobretudo na perspectiva corporativa, faz-se necessário identificar a oportunidade de diálogo como um dos efeitos das redes na sociedade conectada. Os avanços da web em diversos países têm relação profunda com fatores que vão além da própria tecnologia e alçam voo para a dimensão social e a realidade cultural. Essas, de acordo com Rodrigo Alsina (2004, p. 54), podem ser questionadas, então, pelo poder da interculturalidade, que muito se aproxima da questão da ocupação dos espaços e desenvolvimento local.

Por exemplo, o que se pode observar é o desenvolvimento da tecnologia de maneira díspar, com destaque para o desempenho de países como Estados Unidos e certas regiões da Europa, em que existe maior capilaridade da rede de computadores e maior 
largura de banda e velocidade de conexão (Bhagavan, 2001). A fronteira geográfica, todavia, já não é o critério mais importante, considerando-se que a web acaba por definir uma geografia própria, feita de redes e nós que processam fluxos de informação gerados e administrados a partir de qualquer lugar do mundo (Castells, 2003).

Essas novas configurações territoriais representam um desafio do ponto de vista da interculturalidade, pois são criados espaços de fluxos com uma dinâmica própria e que estão em outra perspectiva, que não a do âmbito espacial. Se for levado em consideração que a internet e seus desdobramentos na era da informação estão modificando a estrutura das fronteiras que delimitam os países e seus respectivos blocos geográficos, então é possível pensar em uma política em âmbito global com princípios e valores mais determinantes do que a própria cultura de um povo. Mas será que essa dimensão abstrata representa, de fato, uma mudança no modo como se inter-relacionam diferentes culturas?

A fim de elucidar a questão de uma comunicação nessa instância, é necessário, primeiro, identificar o que pode ser definido como comunicação intercultural. Em seus estudos acerca da interculturalidade, Rodrigo Alsina (2004, p. 60) questiona a própria definição do fenômeno: "Quando podemos dizer que nos encontramos diante de uma comunicação intercultural?". Alinhados a esta pergunta, estão os escritos do francês Ellul (1993), que indicam as cinco condições para que ocorra uma comunicação entre duas ou mais culturas que coexistem em um mesmo conjunto social, a saber: a) diferenças significativas, para que o intercâmbio possa ocorrer adequadamente; b) possibilidade de compreensão para o receptor, apesar das diferenças culturais anteriormente mencionadas; $c$ ) valorização e reconhecimento de ambas as partes, para que grupos diferentes tenham liberdade para questionamentos e novas formas de aprendizado; d) tolerância e aceitação do outro diante das diferenças; e) a distribuição dos meios de comunicação (rádio, televisão, jornais, entre outros) para cada grupo cultural, para que grupos verdadeiramente se conheçam, valorizando o intercâmbio, sem monopolizações.

Os aspectos elencados acima respondem à definição do que se entende por comunicação intercultural. Entretanto, para sua aplicabilidade, a abertura de novos pontos de conexão, a descentralização do know-how tecnológico e a facilitação do acesso igualitário são fundamentais. Ainda longe da plenitude, percebe-se uma evolução no que tange a essas questões: a dependência diante dos Estados Unidos, por exemplo, tem sido gradualmente substituída por técnicas de conexão com redes mais amplas, que ligam os maiores centros metropolitanos de todo o mundo (Castells, 2003).

0 desafio de interconectar o mundo todo consiste em aumentar a rede mundial de computadores em cenários com realidades distintas, a fim de que a proposta de interculturalidade, associada aos tempos da globalização, também se faça presente no âmbito da comunicação. Assim sendo, a comunicação intercultural parte do pressuposto de que a diferenciação dos grupos contempla o intercâmbio, mensagem compreensível, reconhecimento do interlocutor com disposição para abertura eaceitação do outro, especialmente ao respeitar suas diferenças.

No entanto, ao mesmo tempo em que a globalização ocorrida nas últimas décadas representa uma série de oportunidades de relacionamento, ou pelo menos de chegar o mais próximo disso, para uma comunicação intercultural, tal como sugere Rodrigo Alsina, mais complexa se torna a coexistência de diferentes atores/cenários, até mesmo no âmbito corporativo.

Nesse contexto, será que grandes empresas seguem um padrão na contratação de profissionais para o relacionamento com seus públicos ou as mudanças provocadas, principalmente pelas inovações tecnológicas, desorganizaram a estrutura organizacional? É o que os resultados obtidos com uma pesquisa quantitativa tentam evidenciar no próximo item deste artigo. 


\section{GRANDES EMPRESAS E AMBIENTE DIGITAL: AUMENTO DE INTERESSE EM RELACIONAMENTO COM PÚBLICOS E BAIXA INSERÇÃO DO PROFISSIONAL DE RELAÇÕES PÚBLICAS}

Para identificar o principal objetivo das grandes empresas no ambiente digital e averiguar a formação universitária mais procurada por essas respectivas organizações na web, utilizou-se como base uma pesquisa quantitativa realizada por Rafael Vergili (2014), que, na obra original Relações públicas, mercado e redes sociais ainda retrata o perfil completo (faixa etária, sexo, formação acadêmica, entre outras características) dos profissionais responsáveis por esses serviços, além da metodologia completa aplicada.

Resumidamente, no intuito de compor o universo da pesquisa, tomou-se como base inicial de consulta o ranking "Melhores e maiores", divulgado anualmente pela revista Exame(2013). Listadas as mil maiores empresas brasileiras, acessou-se 0 site de cada uma delas, até concluir-se que 252 (25,2\%) possuíam perfil confirmado oficialmente no Twitter' .

Passada a fase de enquadramento aos critérios adotados, foi enviado, entre os dias 04 e 15 de novembro de 2013, um questionário estruturado on-line, de treze questões, para cada uma das grandes empresas, obtendo-se, com método de coleta de dados via autopreenchimento, 128 respostas $(50,8 \%)$.

Depois de tabular os dados, destaca-se o fato de 78,1\% das organizações, a maioria esmagadora, ter como principal objetivo 0 "relacionamento com públicos de interesse". A segunda opção mais assinalada, com distantes 14,8\%, foi o uso da web com 0 intuito de "divulgação de serviços e produtos". Ainda foram indicadas as opções "suporte ao cliente", com 5,5\%, e "transmissão de informações", com reduzidos 1,6\%, como se pode observar no Gráfico 1.

\section{Gráfico 1 - Principal objetivo das empresas no ambiente digital: relacionamento com públicos de interesse.}

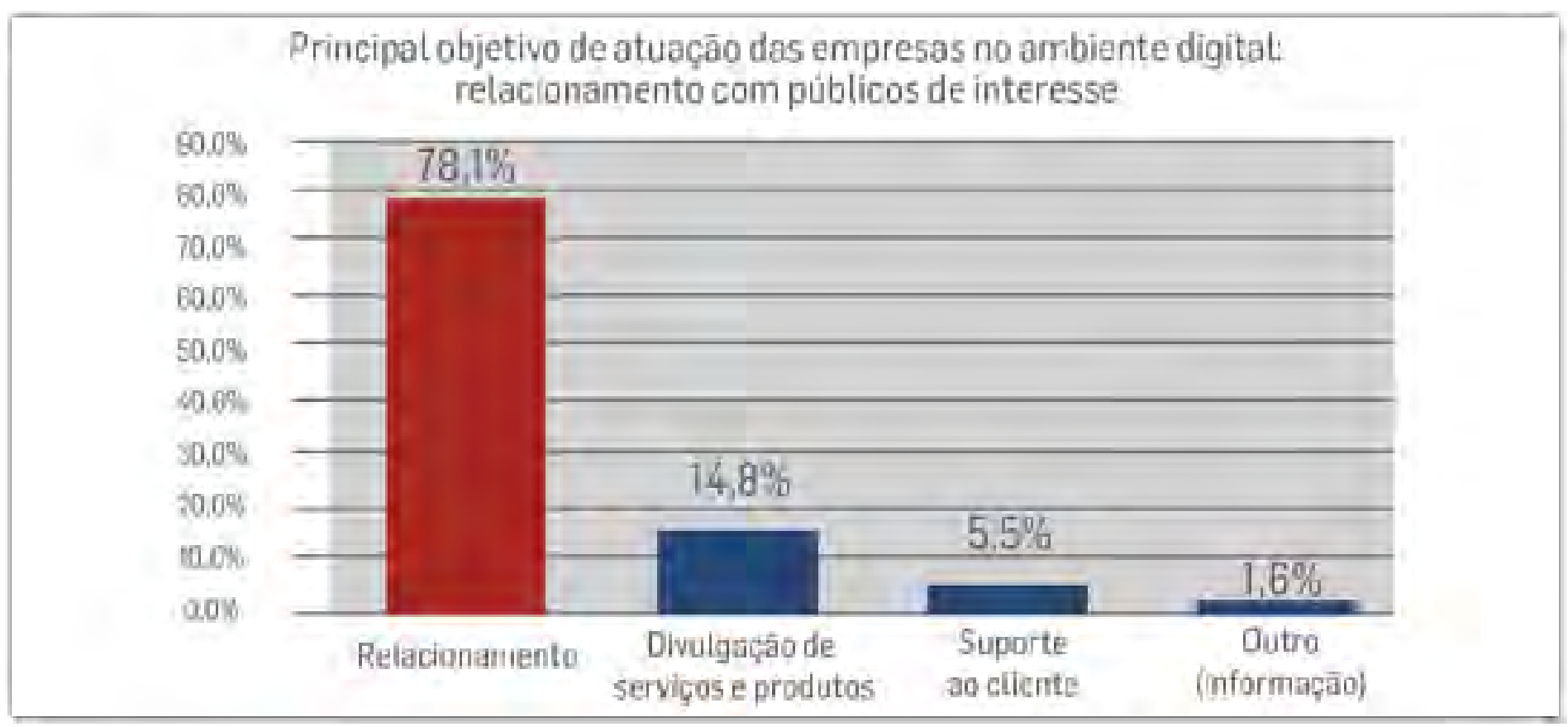

Fonte: Pesquisa realizada por Rafael Vergili (2014). 
Tamanha discrepância entre os objetivos talvez possa ser explicada pelas palavras de Agatha Camargo Paraventi (2011, p. 212), que indica que esse tipo deuso, destinado "aapenas informar os públicos sobre osassuntosque são deinteresseexclusivoda organização, não voltada aos reais interesses dos stakeholders e sem abertura de diálogo, pouco agregará aos objetivos organizacionais".

Todavia, apesar do expressivo percentual alcançado por um objetivo em relação aos outros, o relacionamento, teoricamente uma especialidade de relações públicas, não é traduzido na contratação de seus profissionais para a área. Como apresentado no Gráfico 2, a baixa inserção de relações-públicas neste nicho de mercado (apenas 13,3\%) contrasta com a incontestável predominância de jornalistas, com 40,6\%, e dos também expressivos profissionais de marketing, com 24,2\%, e de publicidade e propaganda, com $19,5 \%$.

Gráfico 2 - Baixa inserção do profissional de relações públicas em departamentos corporativos responsáveis pelo ambiente digital.

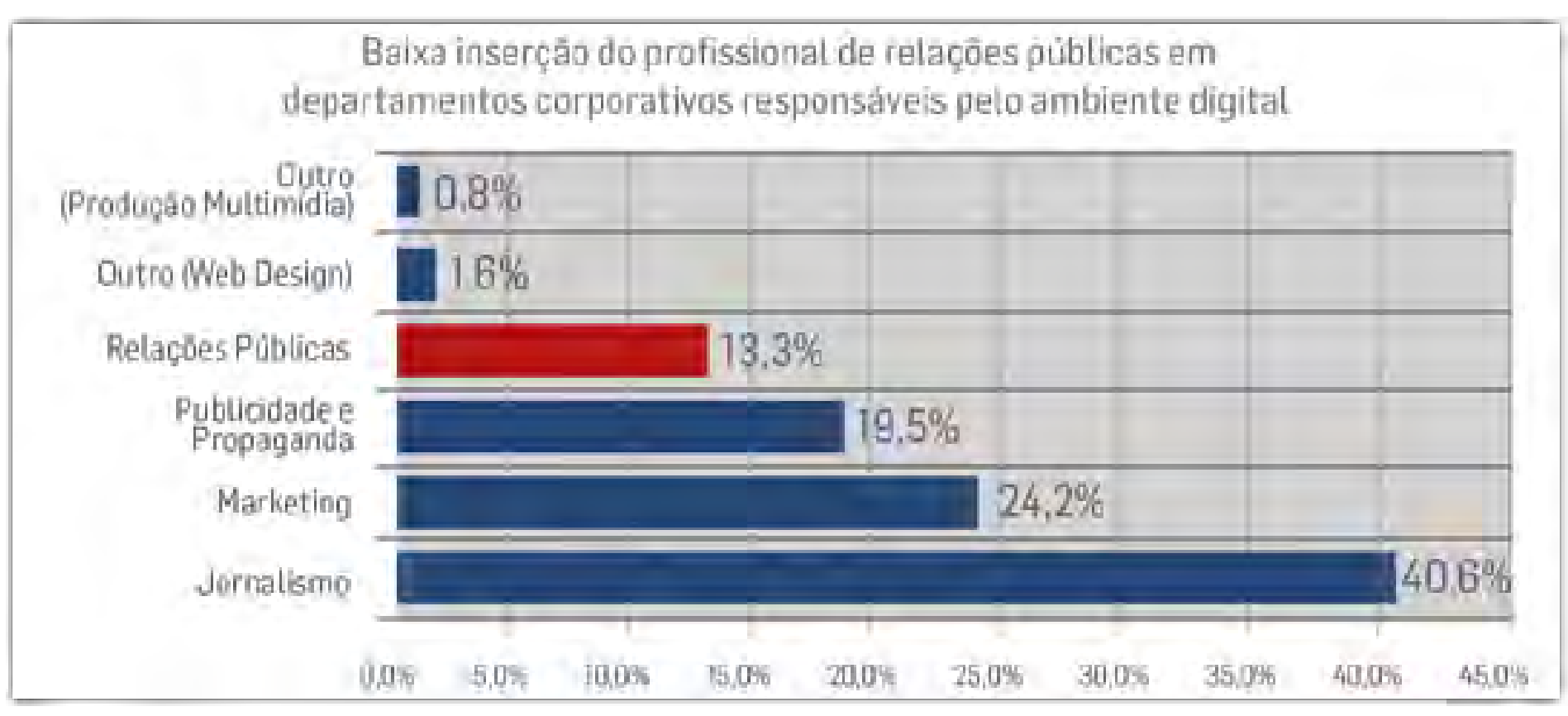

Fonte: Pesquisa realizada por Rafael Vergili (2014).

Uma vez que "o verdadeiro trabalho de relações públicas é aquele que, além de informar, propicia o diálogo" (Kunsch, 2003, p. 106), o paradoxo apontado nas duas questões anteriores motivou a realização de uma pesquisa qualitativa com representantes de agências de comunicação, até para facilitar o entendimento sobre a reduzida inserção dos profissionais de relações públicas nesse nicho de mercado. Alguns trechos das entrevistas em profundidade realizadas poderão ser observados, em contraste com conceitos correlatos, no item a seguir.

\section{AGÊNCIAS DE COMUNICAÇÃO E PROFISSIONAIS DE RELACְ̃̃ES PÚBLICAS EM TEMPOS DE COMUNICAÇÃO INTERCULTURAL}

0 ambiente da web tem sido capaz de revelar o status de uma determinada nação por meio de sua participação ou exclusão do ambiente digital. Ao mesmo tempo em que é consolidado um cenário, com a internet participando da transformação do modo como se dão as relações entre os povos e modificando a dinâmica estabelecida entre as culturas, observa-se a ocorrência de novos contornos aos fluxos de informação que fazem parte do processo da comunicação intercultural. 
Juntamente com os contornos dessa comunicação, aumenta-se o número de organizações que passama coexistir nos ambientes digitais. Nos últimos anos, sobretudo no panorama das empresas brasileiras, tem sido possível acompanhar a modificação da estrutura comunicacional dessas instituições que se encontram diante dos desafios da interculturalidade, ao passo que, inevitavelmente, são levadas a atuar em um universo pautado pela emergência da internet e por seus desdobramentos.

A questão é que as pessoas, cada vez mais, são impelidas a pensar na internet de modo quase irrefutável. Nos dias de hoje, parece não haver saída para organizações que pretendem estabelecer uma comunicação em âmbito global, senão fazer parte do universo on-line. Em uma sociedade conectada - apesar da divisão proveniente da geografia da internet-, não restam muitas opções, além da "presença" (participação) na web, quando se tem interesse em um relacionamento com diferentes públicos cujos princípios se aproximam da definição, anteriormente citada, de comunicação intercultural.

A participação praticamente não se mostra como uma escolha, uma vez que a nova forma de condução dos negócios ganha corpo, especialmente com e na internet (Castells, 2003). É por meio dessa condução pungente de negócios que as organizações passam a repensar o modelo de toda a mecânica envolvida no processo de geração e oferta de produtos e serviços aos consumidores.

Assim, com empresas diante de um cenário cada vez mais desafiador, múltiplo e intercultural, no qual as certezas possuem um princípio de obsolescência, logo, de transitoriedade, a apropriação das novas tecnologias torna-se um imperativo. Pensar o negócio na internet é também rever a comunicação da organização. Isso é o que gerentes, coordenadores e diretores de algumas das maiores agências de comunicação do Brasil (CDN Comunicação Corporativa, Edelman Significa, FSB Comunicações, Grupo Máquina Public Relations, Grupo TV1 Comunicação e Marketing e In Press Porter Novelli ) ${ }^{2}$ indicam nas entrevistas presenciais, realizadas com auxílio de roteiro semiestruturado, entre os dias 09 de maio e 25 de junho de 2012, que compuseram uma pesquisa qualitativa, de natureza exploratória, e que podem ser observadas mais detalhadamente ${ }^{3}$ no livro de Rafael Vergili (2014).

No que tangeà "necessidade" - ou "obrigatoriedade"-que organizações sentem de participar do ambiente digital, especialmente ao notarem que muitas das suas concorrentes estão inseridas no ambiente da web, de acordo com o diretor da Área Digital da Edelman Significa, Daniel Rimoli (2012), em entrevista que nos concedeu,

as empresas procuram o digital como sobrevivência, como necessidade absoluta. 0 digital passou a ser fundamental. Seria como uma pessoa não ter um celular nos dias de hoje. Você não ter uma estratégia digital para a sua empresa é como uma pessoa que não quer ter um celular e depende do telefone fixo que está em sua casa e, dessa maneira, nunca é possível entrar em contato com ela. É inconcebível você pensar que uma empresa tem uma necessidade ou um desafio e que você não solicite, também, uma solução para o ambiente digital de conversação.

Na mesma perspectiva, o coordenador de Mídias Sociais do Grupo TV1 Comunicação e Marketing, Eduardo Gomes Vasques (2012), declarou que

hoje, o que tem acontecido bastante é que alguns dos clientes que nós temos em outras unidades de negócios têm pedido propostas ou, pelo menos, querem entender melhor esse universo de mídias sociais e como eles podem se inserir nesse contexto. (...) 0 que dá para dizer é que existe um crescimento de demanda. Há uma migração de verba bastante nítida do off-line para o on-line.

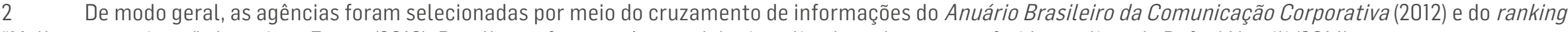
"Melhores e maiores", da revista Exame (2013). Detalhes referentes à metodologia aplicada podem ser conferidos no livro de Rafael Vergili (2014). 


\section{ANO $11 \cdot$ NÚMERO $21 \cdot 2$ - SEM. 2014 • ORGANICOM \\ GRANDES EMPRESAS E INTERCULTURALIDADE: IMPORTÂNCIA DO PROFISSIONAL DE RELAÇÕES PÚBLICAS NO AMBIENTE DIGITAL}

No entanto, seja por necessidade, competitividade, modismo ou tendência, muitas das grandes empresas tentam ser inseridas no ambiente digital sem metas específicas definidas, tendo que recorrer ao apoio ou à entrega total dos serviços às agências. A diretora de Conteúdo e Mídias Digitais da In Press Porter Novelli, Renata Santiago (2012), por exemplo, afirma:

Sinceramente, grande parte precisa ser orientada para definir o principal objetivo. As empresas sabem que precisam estar presentes, sentem essa necessidade, e nos procuram. Esse é o primeiro passo. Então, é frequente uma empresa chegar e dizer: "Eu sei que eu tenho que estar presente, mas eu não sei para qual objetivo". É raro um cliente chegar e falar que quer ser atuante - e existe uma grande diferença entre estar presente e ser atuante.

A gerente de Mídias Sociais da FSB Comunicações, Cynthia Polzer (2012), corrobora essa afirmação ao mencionar que

geralmente [as empresas] não [possuem um objetivo estabelecido]. É muito difícil encontrar algum cliente que especifique. Quando procuram qualquer agência, normalmente não têm noções muito claras do que querem na parte digital. A maioria chega e pede um Twitter, Facebook ou blogue. Muitas vezes a empresa não entende o que é isso, qual é a real função ou necessidade.

Por prestarem serviços externos e lidarem com empresas que muitas vezes não sabem o que desejam no ambiente digital, as agências realizam rápida imersão no cliente para um alinhamento de discurso, tentativa de incutir uma cultura de resposta rápida às demandas - sejam elas críticas, sugestões ou elogios - e definição de objetivos, que geralmente giram em torno do relacionamento com stakeholders, como indicou em entrevista o diretor adjunto da Unidade Digital do Grupo Máquina Public Relations, Rodrigo Barneschi (2012):

Os clientes da Máquina têm uma preocupação muito maior com relacionamento. Até porque a Máquina é uma empresa que trabalha com grandes corporações, que têm uma preocupação muito grande com imagem e reputação. Então, é um trabalho muito forte de relacionamento e dá para observar que os representantes das empresas assessoradas querem entender como elas são percebidas pelo público. (...) Eles querem saber o que as pessoas falam, onde falam e como falam. A partir disso, nós pensamos na estratégia, mas sempre priorizando o relacionamento com os públicos.

Nesse sentido, ao se inserirem em um ambiente intrinsecamente relacionado à globalização e, por consequência, à comunicação intercultural, ter parâmetros determinados previamente e capacidade de readequação de estratégias diante de imprevistos é fundamental para empresas, o que, de certo modo, dialoga com ideias expostas por Margarida Kunsch (2009, p. 195), em estudos que buscam compreender a abrangência e a complexidade organizacional. Nesta seara, destacam-se, também, as funções de relações públicas, situando essa área no âmbito das organizações, destacando seu papel no processo de gestão da comunicação com o universo de públicos existentes e administrando fluxos aquecidos, gerados e mantidos por meio da internet.

Segundo Maria Aparecida Ferrari (2006, p. 87), "a atividade de relações públicas tem duas funções básicas pelas quais atua de forma simultânea e complementar, a saber: a função comunicacional e a função estratégica/gerencial". Por um lado, o processo de relacionamento da organização com os públicos estratégicos é fundamental para a criação de um conceito positivo e duradouro na opinião/atitude e no comportamento das pessoas; por outro, o resultado dessa relação pode e deve agregar valores para ambos os protagonistas: públicos e organização. Luiz Alberto de Farias (2009, p. 145) corrobora esse pensamento ao afirmar que

as relações públicas apresentam, assim, uma função dialógica, por meio da qual criam campo de pensamento que permite o equilíbrio entre interesses por meio de interpretação de significados e da ação pontual ou permanente de integração entre acontecimentos e as suas teias de representações nos espaços simbólicos de disputa e de conflitos e, possivelmente, de encontro e diálogo. 
Talvez um dos paradoxos da relação entre web e relações públicas nos tempos atuais resida exatamente nesta questão, a de relacionamento das organizações com os públicos estratégicos com vistas à criação de uma reputação fortalecida e, ao mesmo tempo, da adaptação a um cenário de constantes mudanças econômicas e sociais advindas das inovações tecnológicas, com a superação das fronteiras, sobretudo no âmbito da geografia da web, e da interculturalidade entre nações de diferentes partes do mundo.

Diante dessa nova realidade, em um cenário de tantas culturas interligadas, mudanças precisam ser incorporadas às tradicionais habilidades do profissional de relações públicas, até para que sua baixa inserção - apresentada anteriormente no artigo - seja revertida ou minimizada. Nessa linha de pensamento, Maria Aparecida Ferrari (2006, p. 88) atenta para 0 desenvolvimento das relações públicas internacionais nas últimas décadas e como sua prática se tornou fundamental no atual cenário organizacional globalizado.

Também a comunicação - e, por extensão, relações públicas - não escapou ao fenômeno da globalização. Baseadas na prática da comunicação nos diferentes contextos políticos, econômicos, sociais e culturais, as relações públicas definem estratégias específicas para cada país ou região, sem perder de vista os fatores intervenientes da globalização, o que nos permite considerálas, em sua dimensão internacional, como uma especialidade das relações públicas, área maior do conhecimento.

Juntamente com o desenvolvimento das relações públicas internacionais, e a busca por uma comunicação intercultural alinhada a uma dimensão global, é de grande valia considerar o comprometimento da área com fatores tecnológicos, em que profissionais devem entender minimamente a lógica do processo digital em que estão inseridos, como aponta o diretor geral da CDN Comunicação Corporativa, Andé Giugliese (2012), também entrevistado na pesquisa qualitativa:

O profissional de comunicação (...) não precisa necessariamente saber programar, mas ele precisa saber interagir com o programador, interagir com o profissional de design. Além do conteúdo, você tem no site ou na rede social, toda a parte visual que é importante para a área de comunicação. 0 profissional de comunicação precisa estar preparado para dialogar com todos esses outros profissionais em um nível que possibilite novas ideias e aplicações.

\section{CONSIDERAÇÕES FINAIS}

De modo geral, pelo contexto apresentado em todo 0 artigo, pode-se dizer que, ainda que o futuro reserve incertezas, 0 quadro delineado demonstra uma oportunidade de aprendizado irrefutável. A internet e o desenvolvimento de suas potencialidades têm transformado o modo como nações se inter-relacionam com suas produções culturais, sugerindo mudanças nas interconexões entre indivíduos e comunidades.

Sobessa ótica, ainda que o cenário globalizado apresente desafios de distintas naturezas, inclusive no âmbito da comunicação intercultural, faz-se necessário reconhecer a importância das relações públicas para o desempenho das organizações no atual modelo de negócios, sempre respeitando preceitos da comunicação intercultural, com compreensibilidade de diferentes grupos, reconhecimento recíproco, aceitação e não monopolização dos meios de comunicação.

A premissa da construção de significado experimentado por seus membros de maneira conjunta é o que parece responder de maneira mais assertiva aos anseios de uma sociedade conectada. Pela pesquisa quantitativa realizada, verificou-se que, 
apesar de buscarem o relacionamento com públicos de interesse, grandes empresas ainda não priorizam a contratação de profissionais de relações públicas, o que depois, com as entrevistas em profundidade com representantes de agências de comunicação, referentes à pesquisa qualitativa, foi uma atitude parcialmente justificada pela defasagem na formação de alguns profissionais, especialmente no que tange ao entendimento tecnológico, à gestão de informações e à administração de diferentes culturas no mesmo ambiente.

Ressalta-se, no entanto, que apesar da necessidade de aprimorar seus conhecimentos, o profissional de relações públicas não precisaria se tornar um programador, mas perceber a lógica do ambiente para coordenar ações, possibilitando o contato mais assertivo com programadores, cientistas da computação e designers, o que permitiria soluções inovadoras para 0 relacionamento (algo que já faz parte da formação de relações públicas) em um contexto tecnológico constantemente alterado. Ou seja, uma busca contínua por deter a parte técnica, visual e de conteúdo, que aproximaria sua formação e suas atividades às de um profissional multifacetado, mediador e com conhecimento unificado. Além disso, o mercado, de certo modo, demanda capacidade analítica para avaliar os riscos e oportunidades advindos do relacionamento com públicos, sobretudo os stakeholders, no ambiente da web.

\section{REFERÊNCIAS}

ANUÁRIO BRASILEIRO DA COMUNICAÇÃO CORPORATIVA 2012. São Paulo: MegaBrasil, 2012.

BHAGAVAN, Malur R. Technological leapfrogging by developing countries. 2001. Disponível em: <http://www.eolss.net/samplechapters/c15/e1-31-01-01.pdf>. Acesso em: 28 ago. 2014.

BARNESCHI, Rodrigo. Entrevista concedida a Rafael Vergili em 06 jun. 2012.

CASTELLS, Manuel. A galáxia da internet. reflexões sobre a internet, os negócios e a sociedade. Trad. de Maria Luiza X. de A. Borges. Rio de Janeiro: Zahar, 2003.

ELLUL, Jacques. Rolê de la communication dans une société pluriculturelle. In: SFEZ, Lucien (Org.). Dictionnaire critique de la communication 1. Paris: Presses Universitaires de France, 1993. p. 494-500.

EXAME. Melhores \& maiores: as 1000 maiores empresas do Brasil. Revista Exame, edição especial dos 40 anos. São Paulo, Editora Abril, 2013.

FARIAS, Luiz Alberto de. Relações públicas e sua função dialógica. Organicom - Revista Brasileira de Comunicação Organizacional e relações Públicas, a. 6, n. 10/11, p. 142-147, 2009.

FERRARI, Maria Aparecida. As dimensões locais das relações públicas internacionais: teorias e paradigmas. Organicom Revista Brasileira de Comunicação Organizacional e relações Públicas, a. 3, n. 5, p. 83-85, 2ํㅗㄴ sem. 2006.

GIULIESE, André. Entrevista concedida a Rafael Vergili em 09 mai. 2012. 
KUNSCH, Margarida Maria Krohling. Planejamento de relações públicas na comunicação integrada. 4. ed. - rev., atual. e ampl. São Paulo: Summus, 2003.

. Relações públicas na gestão estratégica da comunicação integrada nas organizações. In: KUNSCH, Margarida Maria Krohling (Org.). Relações públicas: história, teorias e estratégias nas organizações contemporâneas. São Paulo: Saraiva, 2009.

PARAVENTI, Agatha Camargo. Uso estratégico das publicações na gestão dos relacionamentos organizacionais. In: FARIAS, Luiz Alberto de (Org). Relações públicas estratégicas: técnicas, conceitos e instrumentos. São Paulo: Summus, 2011. p. 195-234.

PASSARELLI, Brasilina. Literacias emergentes nas redes sociais: estado da arte e pesquisa qualitativa no Observatório da Cultura Digital. In: PASSARELLI, Brasilina; AZEVEDO, José (Org.). Atores em rede: olhares luso-brasileiros. São Paulo: Editora Senac São Paulo, 2010.

POLZER, Cynthia. Entrevista concedida a Rafael Vergili em 25 jun. 2012.

RIMOLI, Daniel. Entrevista concedida a Rafael Vergili em 19 jun. 2012.

RODRIGO ALSINA, Miguel. Cuestionamientos, características y miradas de la interculturalidad. Revista Sphera Pública, Murcia, n. 4, p. 53-68, 2004. Disponível em: <https://ddd.uab.cat/pub/artpub/2004/117074/ sphpub_a2004n4p53.pdf>. Acesso em: 28 jul. 2014.

SANTIAGO, Renata. Entrevista concedida a Rafael Vergili em 19 jun. 2012.

VASQUES, Eduardo Gomes. Entrevista concedida a Rafael Vergili em 11 maio 2012.

VERGILI, Rafael. Relações públicas, mercado e redes sociais. São Paulo: Summus Editorial, 2014.

Artigo recebido em 02.09.2014 e aprovado em 17.10.2014. 